\title{
Resolution of foveal detachment in dome-shaped macula after treatment by spironolactone: report of two cases and mini-review of the literature
}

This article was published in the following Dove Press journal:

Clinical Ophthalmology

20 May 2014

Number of times this article has been viewed

\author{
Ali Dirani' \\ Alexandre Matet ${ }^{\prime}$ \\ Talal Beydoun ${ }^{2}$ \\ Irmela Mantel' \\ Francine Behar-Cohen ${ }^{1-3}$ \\ 'Department of Ophthalmology, \\ University of Lausanne, Jules Gonin \\ Eye Hospital, Lausanne, Switzerland; \\ 2Department of Ophthalmology, \\ Hôtel-Dieu de Paris Hospital, \\ Assistance Publique - Hôpitaux de \\ Paris, Paris, France; ${ }^{3}$ Inserm UMRS872, \\ Physiopathology of Ocular Diseases: \\ Therapeutic Innovations, Centre \\ de Recherche des Cordeliers, Paris, \\ France
}

\begin{abstract}
Dome-shaped macula (DSM) was recently described in myopic patients as a convex protrusion of the macula within a posterior pole staphyloma. The pathogenesis of DSM and the development of associated serous foveal detachment (SFD) remain unclear. The obstruction of choroidal outflow and compressive changes of choroidal capillaries have been proposed as causative factors. In this paper, we report two cases of patients with chronic SFD associated with DSM treated with oral spironolactone. After treatment, there was a complete resolution of SFD in both patients. To the best of our knowledge, this is the first report of successful treatment of SFD in DSM by a mineralocorticoid receptor antagonist.
\end{abstract}

Keywords: serous foveal detachment, mineralocorticoid receptor antagonist, dome-shaped macula, treatment

\section{Introduction}

Dome-shaped macula (DSM) was recently described by Gaucher et al in myopic patients as a convex protrusion of the macula within a posterior pole staphyloma. DSM is associated more frequently with a high level of myopia or elevated eye axial length, but in $30 \%$ of cases, it is diagnosed in eyes with low refractive error. ${ }^{1}$ DSM can be complicated by serous foveal detachment (SFD), which usually produces a decrease in visual acuity and which is best diagnosed by high-resolution spectral-domain optical coherence tomography (SD-OCT). The prevalence of SFD in DSM is highly variable according to existing studies and fluctuates between $6 \%$ and $52 \%{ }^{1-4}$ In myopic eyes, the diagnosis of SFD complicating DSM can be challenging since it should be differentiated from other conditions associated with subretinal fluid (SRF) in the macular area, such as myopic choroidal neovascularization, idiopathic central serous chorioretinopathy, neovascular age-related macular degeneration, and polypoidal choroidal vasculopathy. The pathogenesis of DSM and the mechanism leading to the development of SFD are still unclear. Whether treatment should be attempted to reduce SFD and which treatment should be proposed remain unknown. In the literature, one paper describes spontaneous resolution of SFD associated with DSM in one patient, ${ }^{5}$ and a second report describes a regression of SRF following half-fluence photodynamic therapy (PDT) in two patients. ${ }^{6}$

Herewith, we report two cases of SFD associated with DSM that were successfully treated with spironolactone. To the best of our knowledge, this is the first report of efficient treatment of SFD in DSM by a mineralocorticoid receptor (MR) antagonist.

\section{Patient I}

A 53-year-old Caucasian female patient was referred to our hospital for blurred central vision in her right eye. Over the past few weeks, she had noticed a decrease 
in vision and progressive metamorphopsia. Her past medical history was remarkable for scleroderma efficiently controlled by oral mycophenolate mofetil (1 g daily). Upon initial examination, her best-corrected visual acuity (BCVA) was 0.8 and 1.0 (decimal scale) in her right and left eyes, respectively. The patient had moderate myopia with a spherical equivalent of $-3.25 \mathrm{D}$ in both eyes. No significant findings were observed in the anterior segment or vitreous of either eye. Funduscopy showed bilateral tilted optic disc and bilateral inferonasal staphyloma with few foveal pigmentary changes in both eyes. In her right eye, fluorescein angiography and indocyanine green angiography (HRA2; Heidelberg Engineering GmbH, Heidelberg, Germany) did not show evidence of choroidal neovascularization (Figure 1A). SD-OCT (Spectralis; Heidelberg Engineering $\mathrm{GmbH}$ ) showed a DSM in both eyes and SFD in the symptomatic right eye (Figure 1B). The patient was first treated with oral acetazolamide $250 \mathrm{mg}$ three times daily but did not show any improvement after 2 months of therapy (Figure 1C). An intravitreous injection of $1.25 \mathrm{mg}$ of bevacizumab (Avastin ${ }^{\circledR}$; Genentech, South San Francisco, CA, USA) was performed 1 month later but BCVA and SD-OCT were unchanged. At 4 months after presentation, no improvement was noted; a course of oral spironolactone (Aldactone $^{\circledR}$; Pfizer, New York, NY, USA) was prescribed ( $75 \mathrm{mg}$ once daily for $2 \mathrm{months}$ ) after giving a written informed consent for off-label use. Two months later, BCVA improved to 1.0 in the right eye, the metamorphopsia resolved, and the
SFD that had been observed since the initial visit disappeared completely on SD-OCT (Figure 1D). The patient was maintained on oral spironolactone and followed on a routine basis in our department with no recurrence of the SRF at 3 months post-resolution of SFD.

\section{Patient 2}

A 54-year-old Caucasian female patient who was followed in our hospital complained of distortions and deterioration of vision in her right eye that started 3 months prior to the initial examination. Upon examination, BCVA was 0.3 and 0.5 in the right and left eyes, respectively. The patient had undergone cataract surgery 2 years before the initial examination. Prior to surgery, she had bilateral high myopia with a spherical equivalent of $-20 \mathrm{D}$ and $-23 \mathrm{D}$ in her right and left eyes, respectively, that was reduced to $-3 \mathrm{D}$. No significant findings were observed in the anterior segment or vitreous of either eye. Fundoscopy showed bilateral posterior staphyloma with some macular pigmentary changes in both eyes. Fluorescein angiography and indocyanine green angiography (HRA2) of the right eye did not show evidence of choroidal neovascularization (Figure 2A). SD-OCT (Spectralis) showed a DSM in both eyes with SFD only in the right eye (Figure 2B). The patient was treated with increasing doses of oral spironolactone (25 mg once daily for 1 week and $50 \mathrm{mg}$ once daily thereafter) after giving a written informed consent for off-label use of spironolactone. Two months later, the BCVA improved to 0.4 in the right eye, the metamorphopsia
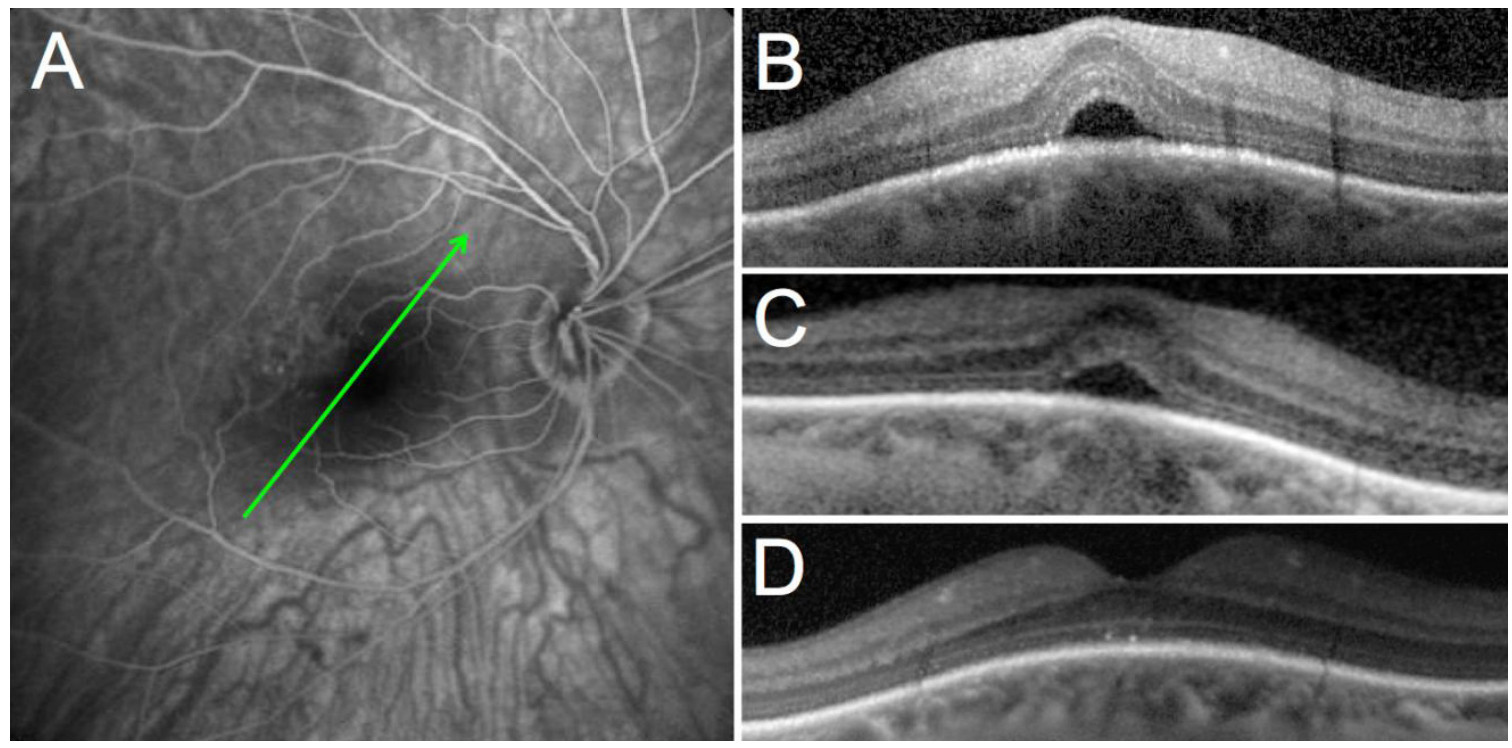

Figure I Case I: 53-year-old female patient.

Notes: (A) Late phase fluorescein angiography showing no sign of choroidal neovascularization or other causes of vascular leakage; (B) macular OCT of the right eye at presentation; (C) macular OCT after treatment with acetazolamide; (D) macular OCT after treatment with spironolactone. The green arrows indicate the level of the B-scan OCT sections.

Abbreviation: OCT, optical coherence tomography. 

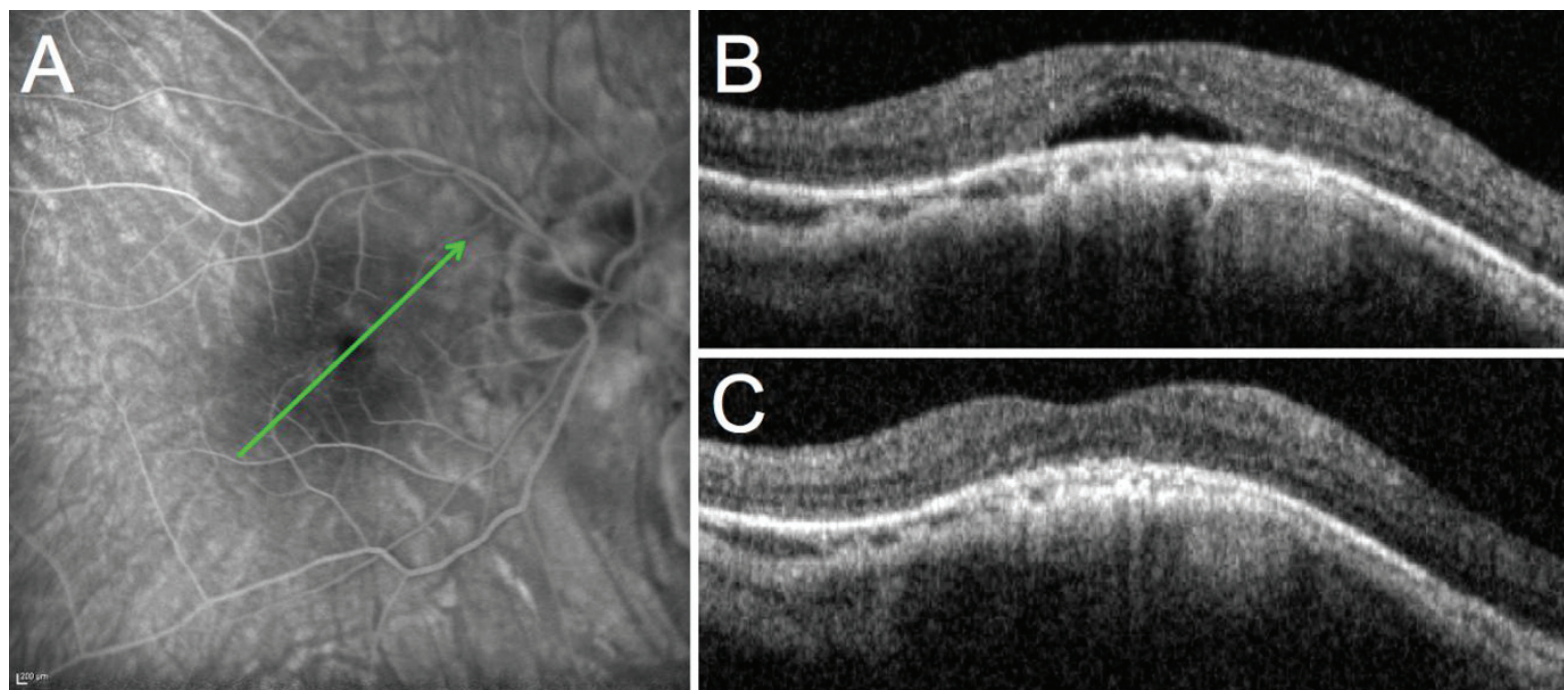

Figure 2 Case 2: 54-year-old female patient.

Notes: (A) Late phase fluorescein angiography showing no sign of choroidal neovascularization or other causes of vascular leakage; (B) macular OCT of the right eye at presentation; (C) macular OCT after treatment with spironolactone. The green arrows indicate the level of the B-scan OCT sections.

Abbreviation: OCT, optical coherence tomography.

were reduced, and the SFD seen at the initial visit disappeared (Figure 2C). The patient was maintained on a low dose of oral spironolactone ( $25 \mathrm{mg}$ once daily) for 6 months and was followed up for 1 year with no recurrence of the SFD.

\section{Discussion}

Several hypotheses have been advanced to explain the development of DSM, such as a resistance to deformation of scleral staphyloma, ${ }^{1}$ localized choroidal thickening in the macular area, ${ }^{1}$ ocular hypotony, ${ }^{7}$ scleral infolding through collapse of the posterior portion of the eye wall, ${ }^{7}$ and tangential vitreoretinal traction. ${ }^{7}$ More recently, Imamura et al demonstrated that DSM may be the result of a localized relative thickness variation of the sclera under the macula in highly myopic patients. ${ }^{3}$

The pathogenesis of SRF accumulation in DSM also remains incompletely understood. Imamura et al suggested a fluid barrier mechanism caused by the thickened sclera, with severe obstruction in the outflow of choroidal fluid that may contribute to the development of SFD in DSM. ${ }^{3}$ Byeon and Chu proposed the term "scleral compression maculopathy", where compressive changes of the choroid and choriocapillaris, and secondary retinal pigment epithelium alterations, may explain the development of SFD in DSM. These changes are characteristically seen along the margin of the myopic staphyloma. ${ }^{8}$

According to Caillaux et al SFD is more common in patients with higher macular bulges and in vertically oriented oval-shaped domes. ${ }^{2}$ The choroidal thickness is significantly greater (near normal) in the foveal area (on the top of the dome) than at the borders of the dome. However, the relationship between macular choroidal thickness and SFD is not well understood. ${ }^{2}$

There are only a few published reports of successful treatment of SFD associated with DSM. Two studies describe the unsuccessful use of argon laser photocoagulation for the treatment of SFD in DSM. ${ }^{1,9}$ According to a report by Chinskey and Johnson ${ }^{6}$ half-fluence verteporfin PDT (Visudyne ${ }^{\circledR}$; Novartis AG, Basel, Switzerland) was employed in two patients with chronic SFD associated with DSM. Following a single treatment, SFD resolved completely in both cases with subjective improvement of visual symptoms. One patient had recurrence of submacular fluid 2 years later that responded incompletely to repeated half-fluence PDT treatment. Subsequent treatment with argon laser photocoagulation led to complete resolution of SRF. ${ }^{6}$ In contrast, use of repeated intravitreal anti-vascular endothelial growth factor injections did not result in resolution of SFD associated with DSM, as reported by Chinskey and Johnson. ${ }^{6}$ Interestingly, Tamura et al reported a patient with bilateral SFD associated with DSM. The SFD resolved spontaneously in both eyes after 1 month. However, it recurred in one eye on the following month and again, resolved spontaneously. ${ }^{5}$ Patients with SRF associated to DSM are relatively younger than patients with age-related maculopathy. They have a healthier retinal pigment epithelium and higher chance of spontaneous resolution of SRF.

We have shown that MR antagonists are efficient for reducing SRF associated with central serous 
chorioretinopathy. ${ }^{10,11}$ In the rat choroid, a potassium channel (SK3) that belongs to the endothelial-derived relaxing factors, has been identified as a mineralocorticoid target involved in choroidal vasodilation. ${ }^{10}$ However, other mineralocorticoid molecular targets may contribute to the effect of spironolactone, particularly in the retinal pigment epithelial cells, which express the MR. ${ }^{12}$ We therefore hypothesized that in addition to compressive and obstructive forces, previously proposed as primum movens for the development of SFD, other mechanisms involving the mineralocorticoid pathway could be involved. Spironolactone is a well-known MR antagonist, used orally to treat many systemic diseases, and it does not expose to any potential choroidal occlusion unlike PDT. In the two patients presented herein, spironolactone seems to have had beneficial effects. Although additional randomized, controlled studies are needed to confirm the efficacy of this novel therapeutic approach of SFD associated with DSM, the risk/benefit ratio of oral spironolactone makes it an acceptable option for patients presenting non-resolving SRF associated with significant visual symptoms.

\section{Disclosure}

The authors report no conflicts of interest in this work.

\section{References}

1. Gaucher D, Erginay A, Lecleire-Collet A, et al. Dome-shaped macula in eyes with myopic posterior staphyloma. Am J Ophthalmol. 2008;145(5):909-914.
2. Caillaux V, Gaucher D, Gualino V, Massin P, Tadayoni R, Gaudric A. Morphologic characterization of dome-shaped macula in myopic eyes with serous macular detachment. Am J Ophthalmol. 2013;156(5): 958-967.e1.

3. Imamura Y, Iida T, Maruko I, Zweifel SA, Spaide RF. Enhanced depth imaging optical coherence tomography of the sclera in dome-shaped macula. Am J Ophthalmol. 2011;151(2):297-302.

4. Ellabban AA, Tsujikawa A, Matsumoto A, et al. Three-dimensional tomographic features of dome-shaped macula by swept-source optical coherence tomography. Am J Ophthalmol. 2013;155(2):320-328.e2.

5. Tamura N, Sakai T, Tsuneoka H. Spontaneous resolution of foveal detachment in dome-shaped macula observed by spectral domain optical coherence tomography. Clin Ophthalmol. 2014;8:83-86.

6. Chinskey ND, Johnson MW. Treatment of subretinal fluid associated with dome-shaped macula. Ophthalmic Surg Lasers Imaging Retina. 2013;44(6):593-595.

7. Mehdizadeh M, Nowroozzadeh MH. Dome-shaped macula in eyes with myopic posterior staphyloma. Am J Ophthalmol. 2008;146(3):478; author reply 478-479.

8. Byeon SH, Chu YK. Dome-shaped macula. Am J Ophthalmol. 2011;151(6):1101; author reply 1101-1102.

9. Pardo-López D, Gallego-Pinazo R, Mateo C, et al. Serous macular detachment associated with dome-shaped macula and tilted disc. Case Rep Ophthalmol. 2011;2(1):111-115.

10. Zhao M, Célérier I, Bousquet E, et al. Mineralocorticoid receptor is involved in rat and human ocular chorioretinopathy. $J$ Clin Invest. 2012;122(7):2672-2679.

11. Bousquet E, Beydoun T, Zhao M, Hassan L, Offret O, BeharCohen F. Mineralocorticoid receptor antagonism in the treatment of chronic central serous chorioretinopathy: a pilot study. Retina. 2013;33(10):2096-2102.

12. Zhao M, Valamanesh F, Celerier I, et al. The neuroretina is a novel mineralocorticoid target: aldosterone up-regulates ion and water channels in Müller glial cells. FASEB J. 2010;24(9):3405-3415.
Clinical Ophthalmology

\section{Publish your work in this journal}

Clinical Ophthalmology is an international, peer-reviewed journal covering all subspecialties within ophthalmology. Key topics include: Optometry; Visual science; Pharmacology and drug therapy in eye diseases; Basic Sciences; Primary and Secondary eye care; Patient Safety and Quality of Care Improvements. This journal is indexed on Submit your manuscript here: http://www.dovepress.com/clinical-ophthalmology-journal

\section{Dovepress}

PubMed Central and CAS, and is the official journal of The Society of Clinical Ophthalmology (SCO). The manuscript management system is completely online and includes a very quick and fair peer-review system, which is all easy to use. Visit http://www.dovepress.com/ testimonials.php to read real quotes from published authors. 